\title{
Treadmill exercise ameliorates nicotine withdrawal-induced symptoms
}

\author{
Sang-Seo Park', Mal-Soon Shin², Hye-Sang Park', Tae-Woon Kim ${ }^{1,3}$, Chang-Ju Kim', Baek-Vin Lim,** \\ 'Department of Physiology, College of Medicine, Kyung Hee University, Seoul, Korea \\ ${ }^{2}$ School of Global Sport Studies, Korea University, Sejong, Korea \\ ${ }^{3}$ Exercise Rehabilitation Research Institute, Department of Sport \& Health Science, Sangmyung University, Seoul, Korea \\ ${ }^{4}$ Division of Leisure \& Sports Science, Department of Exercise Prescription, Dongseo University, Busan, Korea
}

Nicotine withdrawal symptoms comprise insomnia, depression, anxiety, attention disorders, and increased craving. We evaluated the ameliorating effect of treadmill exercise on nicotine withdrawal symptoms. The rats in the nicotine withdrawal groups received subcutaneous injection with $6-\mathrm{mg} / \mathrm{kg}$ nicotine hydrogen tartrate salt for 17 days. And then, the injection of nicotine hydrogen tartrate salt was stopped next for 2 weeks. The rats in the exercise groups performed treadmill running once a day, 5 days per week, for 31 days. In the present results, activity was decreased and anxiety-like behavior was observed in the nicotine withdrawal rats. Treadmill running increased activity and ameliorated anxiety-like behavior in the nicotine-withdrawal rats. Expressions of tryptophan hydroxylase (TPH) and 5-hydroxytryptamine (5-HT) in the dorsal raphe were decreased in the nicotine withdrawal rats, in contrast, treadmill running increased TPH and 5-HT expressions. Impaired short-term memory and deteriorated spatial learning ability were observed in the nicotine withdrawal rats, in contrast, treadmill running ameliorated impairment of short-term memory and spatial learning ability. Expressions of brain-derived neurotrophic factor and tyrosine kinase $B(T r k B)$ were decreased in the nicotine withdrawal rats, in contrast, treadmill running increased brain-derived neurotrophic factor and TrkB expressions. The numbers of the dou-blecortin (DCX)-positive cells and 5-bromo-2' -deoxyuridine (BrdU)-positive cells in the dentate gyrus were suppressed in the nicotine withdrawal rats, in contrast, treadmill running enhanced the numbers of DCX-positive cells and BrdU-positive cells. The present study demonstrate that treadmill exercise ameliorated nicotine withdrawal-induced anxiety, depression, and memory impairment.

Keywords: Nicotine, Treadmill exercise, Anxiety, Depression, Neurogenesis

\section{INTRODUCTION}

Smokers try to stop smoking but many of them fail to stop smoking. The major cause of fail to stop smoking is the nicotine dependence. Nicotine dependence is associated with several neurotransmitters, such as dopamine, noradrenaline, 5-hydroxytryptamine, acetylcholine, etc. (George and O'Malley, 2004). Nicotine withdrawal symptoms comprise insomnia, depression, anxiety, attention disorders, and increased craving (Chae et al., 2008; Kenny and Markou, 2001). Antidepressive or antianxiety medications are often administered with nicotine withdrawal medication. For example, selective serotonin reuptake inhibitors inhibit the reuptake of neurotransmitters and increase serotonin and dopamine levels, thereby reduce anxiety, stress, and depression in nicotine-addicted patients (Harrison et al., 2001). Nicotine withdrawal reduces hippocampal-dependent learning ability (Davis and Gould, 2009; Kenney et al., 2012) which is associated with change in hippocampal nicotinic acetylcholine receptor (Gould et al., 2012).

Serotonin (5-hydroxytryptamine, 5-HT) is a monoamine neurotransmitter, which acts as the biochemical messenger and regulator for the brain function (Kim et al., 2015; Lee et al., 2001). As tryptophan hydroxylase (TPH) is the rate-limiting enzyme for the synthesis of 5-HT, reduction in TPH causes a rapid decrease of 5-HT level (Lee et al., 2001). 5-HT and TPH are involved in the
${ }^{*}$ Corresponding author: Baek-Vin Lim (D) https://orcid.org/0000-0003-4017-573X Division of Leisure \& Sports Science, Department of Exercise Prescription,

Dongseo University, 47 Jurye-ro, Sasang-gu, Busan 47011, Korea

E-mail: todd64@naver.com

Received: February 12, 2019 / Accepted: April 27, 2019
This is an Open Access article distributed under the terms of the Creative Commons Attribution Non-Commercial License (http://creativecommons.org/licenses/by-nc/4.0/) which permits unrestricted non-commercial use, distribution, and reproduction in any medium, provided the original work is properly cited. 
mood regulation (Christiansen et al., 2007).

Brain-derived neurotrophic factor (BDNF) and its receptor, tyrosine kinase $\mathrm{B}(\mathrm{TrkB})$, are widely expressed in the mammalian brain. Hippocampal BDNF is known to be increased by learning and exercise (Cho et al., 2017; Hall et al., 2000). BDNF expression induced by exercise increases neurogenesis and enhances long-term potentiation of the hippocampus (Farmer et al., 2004). BDNF/TrkB signaling modulates neuronal survival, morphogenesis, and plasticity (Numakawa et al., 2010).

Neurogenesis is a process of generating functional neurons from progenitor cells, comprising proliferation, maturation, and functional integration into neuronal circuits. Developing neurons express several markers during maturation process. Detection of 5 bromo-2'-deoxyuridine (BrdU) by immunohistochemistry has been used for phenotypic analysis and stereological quantification of newly formed neurons (Kim et al., 2013; Kim et al., 2017). Neuronal nuclear (NeuN) antigen is regarded as the useful marker of neuronal maturation (Kim et al., 2013; Kim et al., 2017). Doublecortin (DCX) is a marker of neuronal precursor cells, and DCX is implicated in the neuronal migration and development (Kim et al., 2013; Lee et al., 2018).

The effect of exercise on neuropyshicatric disorders are well documented (Cho et al., 2017; Lee et al., 2018; Mead et al., 2008; Seo, 2018). The possibility of exercise to help the cessation of smoking was suggested (Ussher et al., 2014). In the present study, we evaluated the effect of treadmill exercise on nicotine withdrawal-induced symptoms.

\section{MATERIALS AND METHODS}

\section{Experiment animals}

This study was approved by the Kyung Hee University Institutional Animal Care and Use Committee (Seoul, Korea) (KHUASP [SE]-16-152). Male Sprague-Dawley rats (8 weeks old and 200-g weight) were randomly divided into four groups: control group, control with exercise group, nicotine withdrawal group, and nicotine withdrawal with exercise group.

\section{Nicotine injection and withdrawal}

The rats in the nicotine withdrawal groups received subcutaneous injection with 6-mg/kg nicotine hydrogen tartrate salt (Sigma-Aldrich, St. Louis, MO, USA) for 17 days. And then, the injection of nicotine hydrogen tartrate salt was stopped next 2 weeks.

\section{Treadmill exercise}

The rats in the exercise groups performed treadmill running for $5 \mathrm{~min}$ at $8 \mathrm{~m} / \mathrm{min}$, for $5 \mathrm{~min}$ at $11 \mathrm{~m} / \mathrm{min}$, for $30 \mathrm{~min}$ at $14 \mathrm{~m} / \mathrm{min}$, and for $5 \mathrm{~min}$ at $3 \mathrm{~m} / \mathrm{min}$, with 0 inclination. This running was conducted once a day, five days per week, for 31 days.

\section{Open field test}

We determined the activity of rats using open field test, according to the previous method (Seo, 2018). The animals were placed in a white square open field arena made of wood. It was enclosed with 40-cm-high walls and placed under strong illumination (200 Lx). The arena was divided into 16 squares, defined as 4 central and 12 peripheral squares. The animal was placed in the center of the arena and left free to explore the environment for $1 \mathrm{~min}$. After that time, the number of squares that the rat crossed was recorded for 5 min.

\section{Elevated plus-maze test}

Anxiety-like behavior was evaluated using the elevated plus-maze test, according to the previous method (Seo, 2018). The elevated plus-maze test consisted of two opposing open arms $(45 \mathrm{~cm} \times 10 \mathrm{~cm})$ and two closed arms $(45 \mathrm{~cm} \times 10 \mathrm{~cm} \times 50 \mathrm{~cm})$ that extended from a central platform $(10 \mathrm{~cm} \times 10 \mathrm{~cm})$, elevated $65 \mathrm{~cm}$ above the floor. Each rat was placed on the central platform facing a closed arm, and was allowed to freely explore the maze for $5 \mathrm{~min}$. Entry into an arm was defined as entry of all four paws into the arm. The time spent in the open arms and the percentage of the entries into the open arms during 5 min were calculated.

\section{Step-down avoidance test}

In order to evaluate short-term memory, the latency in the stepdown avoidance test was measured, according to the previous method (Cho et al., 2018). The animals were positioned on a $7 \times 25-\mathrm{cm}$ platform with a height of $2.5 \mathrm{~cm}$, and then allowed to rest on the platform for $2 \mathrm{~min}$. The platform faced a $42 \times 25-\mathrm{cm}$ grid of parallel $0.1-\mathrm{cm}$ caliber stainless steel bars, which were spaced $1 \mathrm{~cm}$ apart. In the training session, the animals received 0.3-mA scramble foot shock for 2 sec immediately upon stepping down. Latency time was assessed after $24 \mathrm{hr}$ of training session. The interval of rats stepping down and placing all four paws on the grid was defined as the latency time. The latency over $300 \mathrm{sec}$ was counted as $300 \mathrm{sec}$.

\section{Morris water maze test}

Spatial learning ability was evaluated using the Morris water 
maze test, according to the previous method (Park and Kim, 2017). This task requires rats to learn the spatial location of a hidden platform in a black circular pool $(180-\mathrm{cm}$ diameter and 50$\mathrm{cm}$ height) filled with clear water $\left(25^{\circ} \mathrm{C} \pm 1^{\circ} \mathrm{C}\right)$. The hidden platform (15-cm diameter and $40-\mathrm{cm}$ height) was placed $2 \mathrm{~cm}$ below the surface of water in the middle of the north quadrant and was camouflaged by virtue of being transparent against a black background. Distal visual cues were placed on the walls around the pool. The position of the cues remained unchanged through the task. All rats were trained three times a day for four consecutive days before Morris water maze test.

Morris water maze test was conducted $24 \mathrm{hr}$ after the last training. When finding the platform, the rats were allowed to remain for $30 \mathrm{sec}$. If the rats did not find the platform within $60 \mathrm{sec}$, they were guided by hand to the platform. The rats were given 60 -sec retention probe test, and then the platform removed from the pool. Data were automatically collected via the Smart Video Tracking System (Smart ver. 2.5, Panlab, Barcelona, Spain).

\section{Tissue preparation}

The rats were sacrificed immediately after last behavior test. After anesthetizing using Zoletil $50(10 \mathrm{mg} / \mathrm{kg}$, intraperitoneally; Vibac Laboratories, Carros, France), the rats were transcardially perfused with $50 \mathrm{mM}$ phosphate-buffered saline (PBS) and were fixed with $4 \%$ paraformaldehyde in $100 \mathrm{mM}$ phosphate buffer ( $\mathrm{PB}, \mathrm{pH}$ 7.4). The brains were dissected and post-fixed in the same fixative overnight and transferred into a $30 \%$ sucrose solution for cryoprotection. Using a freezing microtome (Leica, Nussloch, Germany), 40- $\mu \mathrm{m}$-thick sagittal sections were made.

\section{Immunohistochemistry for DCX}

Immunohistochemistry for DCX was performed, according to the previous method (Park and Kim, 2017). The sections were incubated in PBS for 10 min, washed three times in PBS, and then incubated in $1 \%$ hydrogen peroxide for $20 \mathrm{~min}$. The sections were incubated $2 \mathrm{hr}$ with goat anti-DCX antibody (1:1,000; Oncogene Research Product, Cambridge, UK). The sections were then incubated with the biotinylated goat secondary antibody (1:500; Vector Laboratories, Burlingame, CA, USA) for another 1 $\mathrm{hr}$, washed, and incubated in $\mathrm{ABC}$ complex (Vector Elite $\mathrm{ABC}$ kit; 1:100; Vector Laboratories). Labeling was visualized using $0.03 \%$ diaminobenzidine, and the sections were mounted onto gelatin-coated slides. The slides were air-dried overnight at room temperature, and the coverslips were mounted using Permount (Thermo Fisher Scientific Inc., Waltham, MA, USA).

\section{Immunohistochemistry for BrdU}

Immunohistochemistry for BrdU was performed, according to the previous method (Cho et al., 2018). The sections were first permeabilized by incubation in $0.5 \%$ Triton X-100 in PBS for 20 min, then pretreated in $50 \%$ formamide- $2 \mathrm{X}$ standard saline citrate at $65^{\circ} \mathrm{C}$ for $2 \mathrm{hr}$, denatured in $2 \mathrm{~N} \mathrm{HCl}$ at $37^{\circ} \mathrm{C}$ for $30 \mathrm{~min}$, and rinsed twice in $100 \mathrm{mM}$ sodium borate $(\mathrm{pH}, 8.5)$. The sections were then incubated overnight at $4^{\circ} \mathrm{C}$ with $\mathrm{BrdU}$-specific mouse monoclonal antibody (1:600; Roche, Mannheim, Germany). The sections were then washed three times with PBS and incubated with biotinylated mouse secondary antibody (1:200; Vector Laboratories) for $1 \mathrm{hr}$. The sections were then incubated for 1 hr with an ABC complex (1:100; Vector Laboratories). For visualization, the sections were incubated in $50 \mathrm{mM}$ Tris- $\mathrm{HCl}(\mathrm{pH}, 7.6)$ containing $0.03 \%$ diaminobenzidine, $40-\mathrm{mg} / \mathrm{mL}$ nickel chloride, and $0.03 \%$ hydrogen peroxide for $5 \mathrm{~min}$.

After BrdU labeling, a mouse antineuronal nuclei antibody (1:1,000; Chemicon International, Temecula, CA, USA) was used on the same sections to differentiate neurons. The sections were washed 3 times with PBS, incubated for 1 hr with a biotinylated anti-mouse secondary antibody. For staining, the sections were incubated in a reaction mixture consisting of $0.03 \%$ diaminobenzidine and $0.03 \%$ hydrogen peroxide for $5 \mathrm{~min}$. The sections were mounted onto gelatin-coated slides, air-dried overnight at room temperature, and coverslips were mounted using Permount (Thermo Fisher Scientific Inc.).

\section{Immunohistochemistry for TPH and 5-HT}

Immunohistochemistry was performed for the detection of the TPH-positive and 5-HT-positive cells in the dorsal raphe, according to the previous method (Moon et al., 2018). The sections were incubated in PBS for 10 min and they were next washed 3 times with PBS. The sections were then incubated in $1 \%$ hydrogen peroxide for $30 \mathrm{~min}$, and then they were incubated overnight with mouse anti-TPH antibody (Oncogene Research Product) and rabbit anti-5-HT antibody (Oncogene Research Product) at a dilution of 1:500 for TPH and 5-HT expressions. The sections were incubated for $90 \mathrm{~min}$ with biotinylated mouse secondary antibody and with biotinylated rabbit secondary antibody (Vector Laboratories), and they were subsequently incubated with avidin-biotin-peroxidase complex (Vector Laboratories) for $1 \mathrm{hr}$. Immunoreactivity was visualized by incubating the sections in a solution consisting of $0.05 \% 3,3^{\prime}$-diaminobenzidine and $0.01 \%$ hydrogen peroxide in $50 \mathrm{mM}$ Tris-buffer $(\mathrm{pH}, 7.6)$ for approximately 3 min. The sections were finally mounted on gelatin-coated glass 
slides. The slides were air-dried overnight at room temperature, and the coverslips were mounted using Permount (Thermo Fisher Scientific Inc.).

\section{Western blotting for BDNF and TrkB}

Western blotting for the determination of BDNF and TrkB was conducted, according to the previous method (Park et al., 2017). Hippocampal samples were homogenized on ice and lysed in a lysis buffer containing $50 \mathrm{mM}$ Tris- $\mathrm{HCl}(\mathrm{pH}, 7.5), 150 \mathrm{mM}$ $\mathrm{NaCl}, 0.5 \%$ deoxycholic acid, $1 \%$ Nonidet $\mathrm{P} 40,0.1 \%$ sodium dodecyl sulfate (SDS), $1 \mathrm{mM}$ phenylmethylsulfonyl fluoride, and $100 \mathrm{mg} / \mathrm{mL}$ leupeptin. Protein content was measured using a Bio-
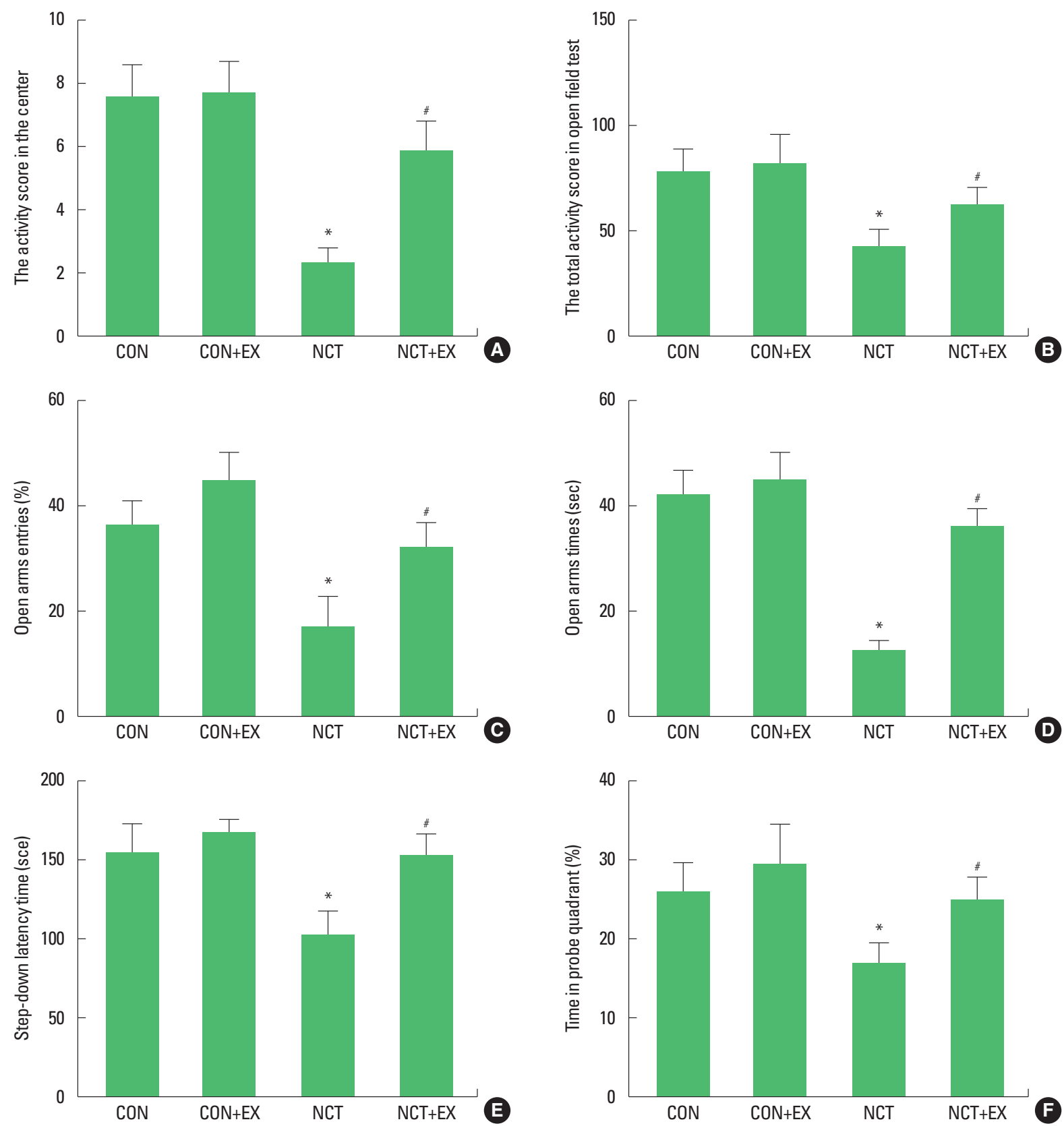

Fig. 1. Behavior test. (A, B) Open field test. (C, D) Elevated plus maze test. (E) Step-down avoidance test. (F) Morris water maze test. CON, control group; CON+EX, control with exercise group; NCT, nicotine withdrawal group; NCT+EX, nicotine withdrawal with exercise group. ${ }^{*} P<0.05$ compared to control group. ${ }^{\sharp} P<0.05$ compared to nicotine withdrawal group. 
Rad colorimetric protein assay kit (Bio-Rad, Hercules, CA, USA). Thirty micrograms of total protein were separated on SDS-polyacrylamide gels and transferred onto a nitrocellulose membrane. The membrane was blocked with dehydrated milk, then incubated with mouse anti- $\beta$-actin antibody (1:1,000; Santa Cruz Biotechnology, Santa Cruz, CA, USA), rabbit anti-BDNF antibody (1:1,000; Santa Cruz Biotechnology), and rabbit anti-TrkB antibody (1:1,000; Santa Cruz Biotechnology). After washing, horseradish peroxidase-conjugated, appropriate secondary antibodies were applied. Incubations were performed at room temperature. The bands were detected using the enhanced chemiluminescence detection system (Santa Cruz Biotechnology), and quantified using an Image-Pro Plus computer-assisted image analysis system (Media Cyberbetics Inc., Silver Spring, MD, USA).

\section{Statistical analysis}

Data were analyzed using IBM SPSS Statistics ver. 21.0 (IBM
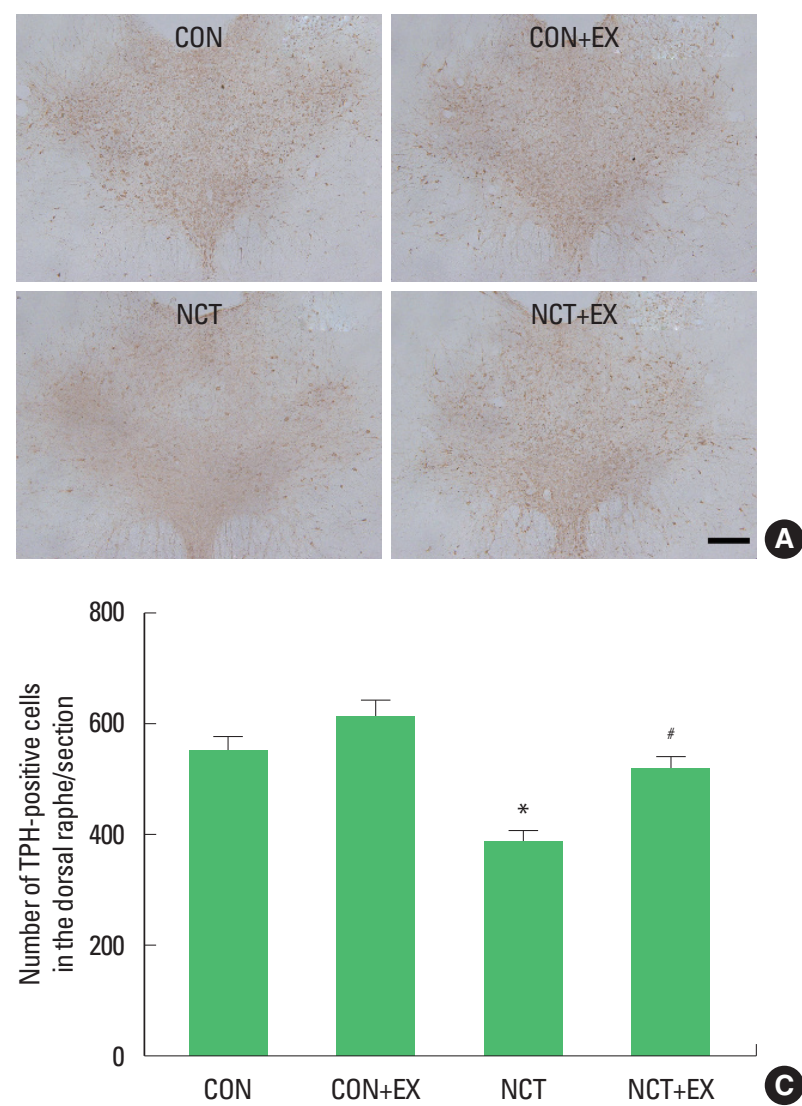

Co., Armonk, NY, USA). The results were expressed as the mean \pm standard error of the mean. One-way analysis of variance with Tukey post hoc test was used for comparison among the groups. $P<0.05$ was considered significant.

\section{RESULTS}

\section{Behavior test}

Fig. 1 shows the results of behavior test in the nicotine withdrawal rats. Activity was measured using the open field test (Fig. $1 \mathrm{~A}, \mathrm{~B})$. Activity scores in the center and total were decreased in the rats of the nicotine withdrawal group $(P<0.05)$, in contrast, treadmill exercise increased scores in the rats of the nicotine withdrawal group $(P<0.05)$. Anxiety-like symptoms were measured using the elevated plus-maze test (Fig. 1C, D). Open arms entries and times were decreased in the rats of the nicotine withdrawal group $(P<0.05)$, in contrast, treadmill exercise increased symptoms
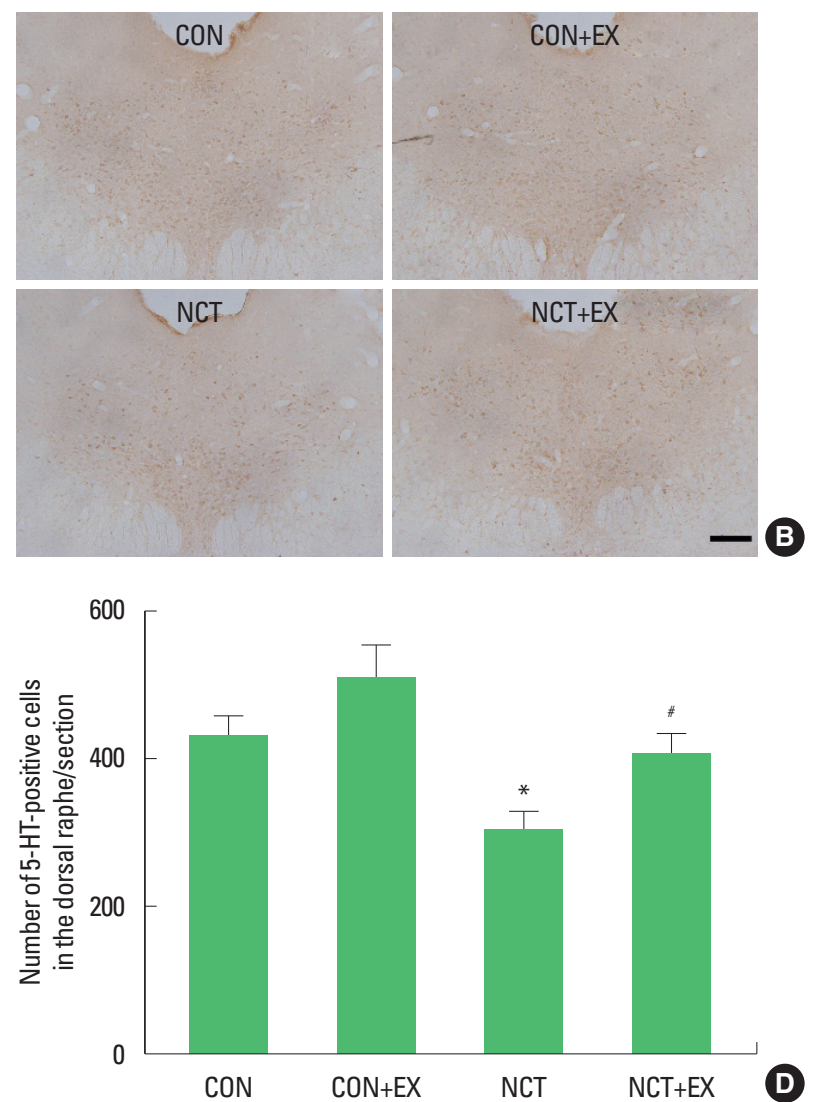

Fig. 2. Tryptophan hydroxylase (TPH) and 5-hydroxytryptamine (5-HT) in the dorsal raphe. (A) Photomicrographs of TPH. (C) The number of TPH-positive cells in each group. (B) Photomicrographs of 5-HT. (D) The number of 5-HT-positive cells in each group. The scale bar represents $200 \mu \mathrm{m}$. CON, control group; CON+EX, control with exercise group; NCT, nicotine withdrawal group; NCT+EX, nicotine withdrawal with exercise group. ${ }^{*} P<0.05$ compared to control group. ${ }^{\#} P<0.05$ compared to nicotine withdrawal group. 
in the rats of the nicotine withdrawal group $(P<0.05)$. Short-term memory was measured using the step-down avoidance test (Fig. $1 \mathrm{E})$. Latency was decreased in the rats of the nicotine withdrawal group $(P<0.05)$, in contrast, treadmill exercise increased latency in the rats of the nicotine withdrawal group $(P<0.05)$. Spatial learning ability was measured using the Morris water maze test (Fig. 1F). Time in probe quadrant was decreased in the rats of the nicotine withdrawal group $(P<0.05)$, in contrast, treadmill exercise increased this time in the rats of the nicotine withdrawal group $(P<0.05)$.

The numbers of TPH-positive and 5-HT-positive cells in the dorsal raphe

Fig. 2 shows the numbers of TPH-positive (Fig. 2A, C) and 5HT-positive cells (Fig. 2B, D) in the dorsal raphe. The numbers of TPH-positive and 5-HT-positive cells were decreased in the rats of the nicotine withdrawal group $(P<0.05)$, in contrast, treadmill exercise increased these numbers in the rats of the nicotine withdrawal group $(P<0.05)$.

\section{The numbers of DCX-positive and BrdU-positive cells in the dentate gyrus}

Fig. 3 shows the numbers of DCX-positive (Fig. 3A, C) and BrdU-positive cells (Fig. 3B, D) in the dentate gyrus. The numbers of DCX-positive and BrdU-positive cells were decreased in the rats of the nicotine withdrawal group $(P<0.05)$, in contrast, treadmill exercise increased these numbers in the rats of the nicotine withdrawal group $(P<0.05)$.

\section{Expressions of BDNF and TrkB in hippocampus}

Fig. 4 shows the expressions of BDNF (Fig. 4B) and $\operatorname{TrkB}$ (Fig. $4 \mathrm{C})$ in the hippocampus. BDNF and $\operatorname{TrkB}$ expressions were decreased in the rats of the nicotine withdrawal group $(P<0.05)$, in contrast, treadmill exercise increased these expressions in the rats
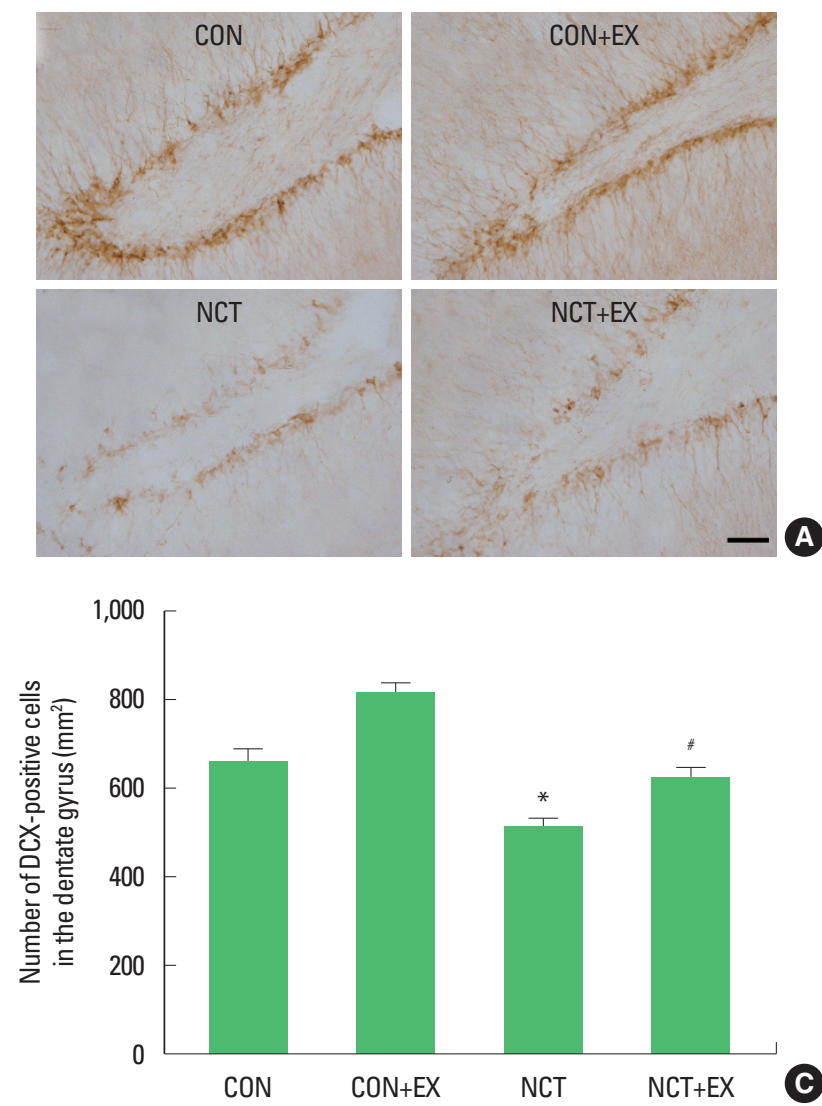
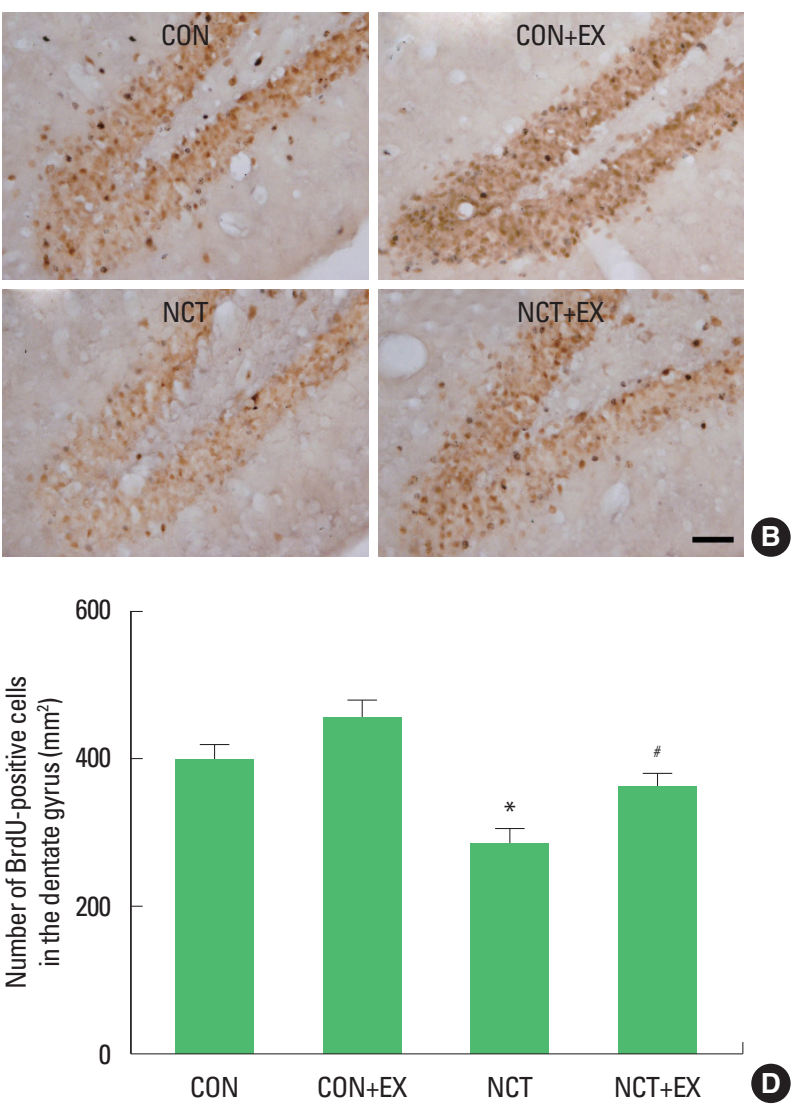

Fig. 3. Cell differentiation and cell proliferation in the dentate gyrus. (A) Photomicrograph of doublecortin (DCX)-positive cells. (C) The number of DCX-positive cells in each group. (B) Photomicrograph of 5-bromo-2'-deoxyuridine (BrdU)-positive cells. (D) The number of BrdU-positive cells in each group. The scale bar represents 500 $\mu \mathrm{m}$ in each group. CON, control group; CON+EX, control with exercise group; NCT, nicotine withdrawal group; NCT+EX, nicotine withdrawal with exercise group. ${ }^{*} P<0.05$ compared to control group. ${ }^{\#} P<0.05$ compared to nicotine withdrawal group. 

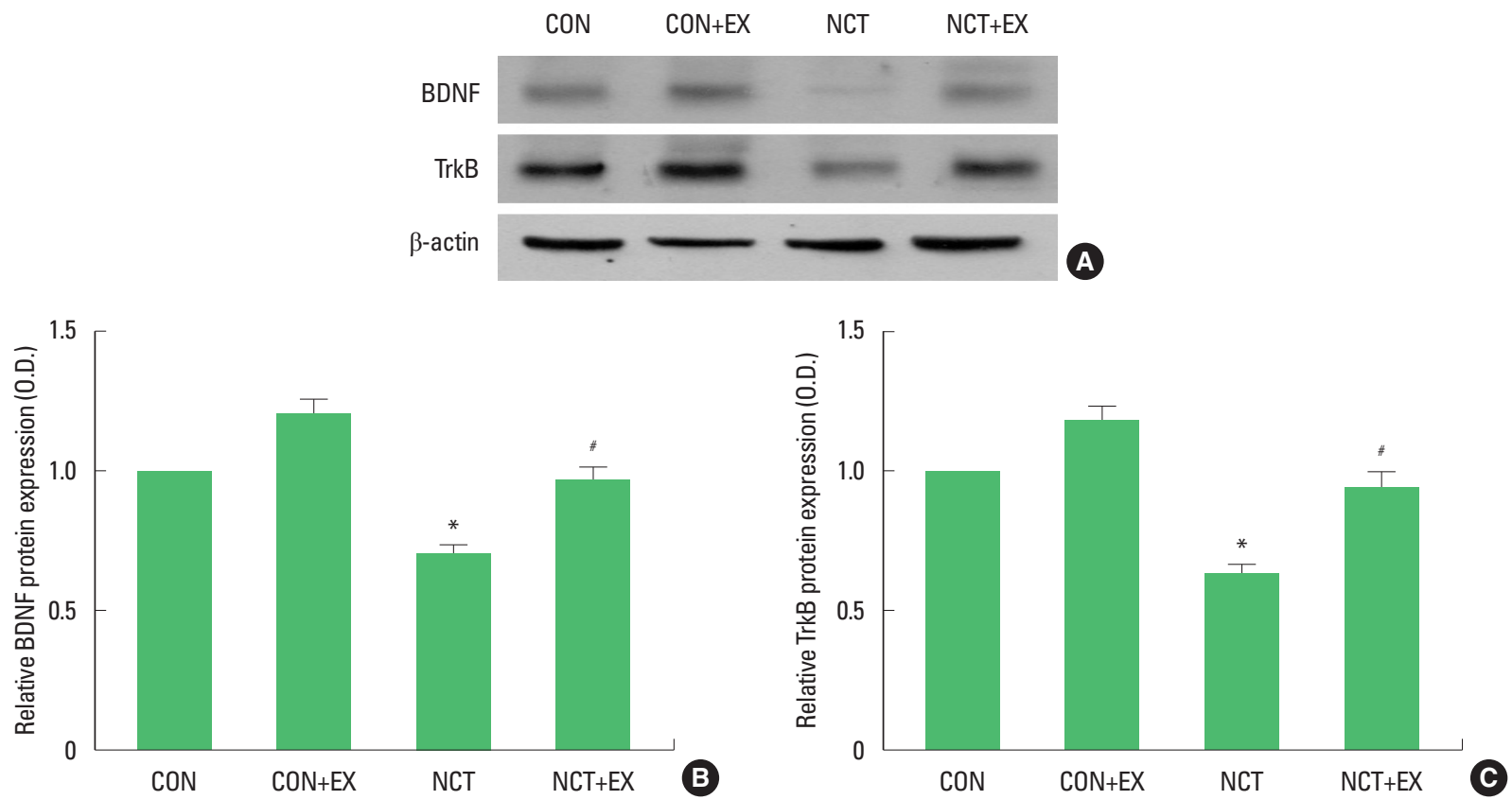

Fig. 4. Brain-derived neurotrophic factor (BDNF) and tyrosine kinase B (TrkB) in the hippocampus. (A) Presentation of BDNF and TrkB expressions. (B) Relative optical density of BDNF in each group. (C) Relative optical density of TrkB in each group. CON, control group; CON+EX, control with exercise group; NCT, nicotine withdrawal group; NCT+EX, nicotine withdrawal with exercise group. ${ }^{*} P<0.05$ compared to control group. ${ }^{\sharp} P<0.05$ compared to nicotine withdrawal group.

of the nicotine withdrawal group $(P<0.05)$.

\section{DISCUSSION}

In the present results, activity was decreased and anxiety-like behavior was observed in the nicotine withdrawal rats. Treadmill running increased activity and ameliorated anxiety-like behavior in the nicotine-withdrawal rats. Under the certain conditions, nicotine acted as anxiolytic and antidepressant. If adaptation to nicotine occurs following chronic nicotine use, nicotine withdrawal caused anxiety and depression (Picciotto et al., 2002). Exercise was suggested as the effective adjunct in lessening the nicotine withdrawal symptoms (Ussher et al., 2014). Treadmill exercise exerted ameliorating effect on severity of anxiety and depression (Cho et al., 2017; Seo, 2018).

In the present results, expressions of TPH and 5-HT in the dorsal raphe were decreased in the nicotine withdrawal rats. Expressions of TPH and 5-HT were increased by treadmill running in the nicotine withdrawal rats. Decreased activity of the brain serotonergic system was implicated in the pathophysiology of depression (Arborelius et al., 2004). 5-HT level was closely associated with depression and adult neurogenesis (Lee et al., 2001; Moon et al., 2018). Treadmill running enhanced expressions of 5-HT and TPH in the dorsal raphe of the social isolation-induced depressive rats (Cho et al., 2017).

In the present results, impaired short-term memory and deteriorated spatial learning ability were appeared in the nicotine withdrawal rats. Treadmill running ameliorated impairment of shortterm memory and spatial learning ability in the nicotine withdrawal rats. Smoking cessation caused a decline of learning ability and attention (Davis and Gould, 2009). Learning ability was decreased after the cessation of chronic nicotine administration because of altered nicotine receptor in the hippocampus (Kenney et al., 2012).

In the present results, expressions of BDNF and TrkB were decreased in the nicotine withdrawal rats. Expressions of BDNF and TrkB were increased by treadmill running in the nicotine withdrawal rats. BDNF has been suggested as a principal mediator of exercise on the overall brain function. Reduction of BDNF was closely related with decrease of neurogenesis (Rasmusson et al., 2002). Reduction of BDNF and decreased neurogenesis were restored by exercise (Cho et al., 2017; Redila and Christie, 2006).

In the present results, the numbers of the DCX-positive cells and BrdU-positive cells in the dentate gyrus were suppressed in the nicotine withdrawal rats. These numbers were enhanced by treadmill running in the nicotine withdrawal rats. Reduced cell proliferation in the dentate gyrus was associated with the impairment of learning and memory function, in contrast, increased cell 
proliferation is associated with the improvement of learning and memory function (Cho et al., 2017; Kim et al., 2017). Exercise increased neurogenesis, and then improved memory function (Cho et al., 2017; Kim et al., 2013; Kim et al., 2017).

The present study demonstrated that treadmill exercise ameliorated nicotine withdrawal-induced anxiety and depression through enhancing 5-HT synthesis in the brain. Treadmill exercise improved memory function against nicotine withdrawal-induced memory impairment through enhancing neurogenesis in the brain. Based on the present results, treadmill exercise can be recommended as the adjunctive treatment to reduce nicotine withdrawal-induced symptoms.

\section{CONFLICT OF INTEREST}

No potential conflict of interest relevant to this article was reported.

\section{ACKNOWLEDGMENTS}

This study was supported by the Ministry of Education of the Republic of Korea and the National Research Foundation of Korea (NRF-2016S1A5A2A01023254).

\section{REFERENCES}

Arborelius L, Hawks BW, Owens MJ, Plotsky PM, Nemeroff CB. Increased responsiveness of presumed 5-HT cells to citalopram in adult rats subjected to prolonged maternal separation relative to brief separation. Psychopharmacology (Berl) 2004;176:248-255.

Chae Y, Yeom M, Han JH, Park HJ, Hahm DH, Shim I, Lee HS, Lee H. Effect of acupuncture on anxiety-like behavior during nicotine withdrawal and relevant mechanisms. Neurosci Lett 2008;430:98-102.

Cho JW, Jung SY, Kim DY, Chung YR, Choi HH, Jeon JW, Han JH. PI3K-

Akt-Wnt pathway is implicated in exercise-induced improvement of short-term memory in cerebral palsy rats. Int Neurourol J 2018;22 (Suppl 3):S156-164.

Cho JW, Jung SY, Lee SW, Lee SJ, Seo TB, Kim YP, Kim DY. Treadmill exercise ameliorates social isolation-induced depression through neuronal generation in rat pups. J Exerc Rehabil 2017;13:627-633.

Christiansen L, Tan Q, Iachina M, Bathum L, Kruse TA, McGue M, Christensen $\mathrm{K}$. Candidate gene polymorphisms in the serotonergic pathway: influence on depression symptomatology in an elderly population. Biol Psychiatry 2007;61:223-230.

Davis JA, Gould TJ. Hippocampal nAChRs mediate nicotine withdraw- al-related learning deficits. Eur Neuropsychopharmacol 2009;19:551561.

Farmer J, Zhao X, van Praag H, Wodtke K, Gage FH, Christie BR. Effects of voluntary exercise on synaptic plasticity and gene expression in the dentate gyrus of adult male Sprague-Dawley rats in vivo. Neuroscience 2004;124:71-79.

George TP, O'Malley SS. Current pharmacological treatments for nicotine dependence. Trends Pharmacol Sci 2004;25:42-48.

Gould TJ, Portugal GS, André JM, Tadman MP, Marks MJ, Kenney JW, Yildirim E, Adoff M. The duration of nicotine withdrawal-associated deficits in contextual fear conditioning parallels changes in hippocampal high affinity nicotinic acetylcholine receptor upregulation. Neuropharmacology 2012;62:2118-2125.

Hall J, Thomas KL, Everitt BJ. Rapid and selective induction of BDNF expression in the hippocampus during contextual learning. Nat Neurosci 2000;3:533-535.

Harrison AA, Liem YT, Markou A. Fluoxetine combined with a serotonin-1A receptor antagonist reversed reward deficits observed during nicotine and amphetamine withdrawal in rats. Neuropsychopharmacology 2001;25:55-71.

Kenney JW, Raybuck JD, Gould TJ. Nicotinic receptors in the dorsal and ventral hippocampus differentially modulate contextual fear conditioning. Hippocampus 2012;22:1681-1690.

Kenny PJ, Markou A. Neurobiology of the nicotine withdrawal syndrome. Pharmacol Biochem Behav 2001;70:531-549.

Kim SE, Han JH, Ko IG, Kim CJ, Kim KH. Alpha1-adrenergic receptor antagonist tamsulosin ameliorates aging-induced memory impairment by enhancing neurogenesis and suppressing apoptosis in the hippocampus of old-aged rats. Anim Cells Syst 2017;21:404-411.

Kim SE, Ko IG, Park CY, Shin MS, Kim CJ, Jee YS. Treadmill and wheel exercise alleviate lipopolysaccharide-induced short-term memory impairment by enhancing neuronal maturation in rats. Mol Med Rep 2013;7:31-36.

Kim TW, Lim BV, Baek D, Ryu DS, Seo JH. Stress-induced depression is alleviated by aerobic exercise through up-regulation of 5-hydroxytryptamine 1A receptors in rats. Int Neurourol J 2015;19:27-33.

Lee HJ, Kim JW, Yim SV, Kim MJ, Kim SA, Kim YJ, Kim CJ, Chung JH. Fluoxetine enhances cell proliferation and prevents apoptosis in dentate gyrus of maternally separated rats. Mol Psychiatry 2001;6:610, 725-728.

Lee JM, Ji ES, Kim TW, Kim CJ, Shin MS, Lim BV, Chung YR, Cho YS. Treadmill exercise improves memory function by inhibiting hippocampal apoptosis in pilocarpine-induced epileptic rats. J Exerc Rehabil 2018;14:713-723.

Mead GE, Morley W, Campbell P, Greig CA, McMurdo M, Lawlor DA. 
Exercise for depression. Cochrane Database Syst Rev 2008;(4): CD004366.

Moon EJ, Ko IG, Kim SE, Jin JJ, Hwang L, Kim CJ, An H, Lee BJ, Yi JW. Dexmedetomidine ameliorates sleep deprivation-induced depressive behaviors in mice. Int Neurourol J 2018;22(Suppl 3):S139-146.

Numakawa T, Suzuki S, Kumamaru E, Adachi N, Richards M, Kunugi H. BDNF function and intracellular signaling in neurons. Histol Histopathol 2010;25:237-258.

Park HS, Kim TW. Paternal physical exercise improves spatial learning ability by enhancing hippocampal neuroplasticity in male pups born from obese maternal rats. J Exerc Rehabil 2017;13:266-272.

Park JH, Ko IG, Kim SE, Jin JJ, Hwang L, Kim CJ, Yoon SH, Hong J, Chung JY, Lee DW. Dexmedetomidine oral mucosa patch for sedation suppresses apoptosis in hippocampus of normal rats. Int Neurourol J
2017;21(Suppl 1):S39-47.

Picciotto MR, Brunzell DH, Caldarone BJ. Effect of nicotine and nicotinic receptors on anxiety and depression. Neuroreport 2002;13:1097-1106.

Rasmusson AM, Shi L, Duman R. Downregulation of BDNF mRNA in the hippocampal dentate gyrus after re-exposure to cues previously associated with footshock. Neuropsychopharmacology 2002;27:133142.

Redila VA, Christie BR. Exercise-induced changes in dendritic structure and complexity in the adult hippocampal dentate gyrus. Neuroscience 2006;137:1299-1307.

Seo JH. Treadmill exercise alleviates stress-induced anxiety-like behaviors in rats. J Exerc Rehabil 2018;14:724-730.

Ussher MH, Taylor AH, Faulkner GE. Exercise interventions for smoking cessation. Cochrane Database Syst Rev 2014;(8):CD002295. 